\title{
Experimental evaluation of protection and immunogenicity of Streptococcus suis bacterin-based vaccines formulated with different commercial adjuvants in weaned piglets
}

Milan R. Obradovic, Lorelei Corsaut, Dominic Dolbec, Marcelo Gottschalk* and Mariela Segura* (0)

\begin{abstract}
Streptococcus suis is an important swine pathogen responsible for economic losses to the swine industry worldwide. There is no effective commercial vaccine against S. suis. The use of autogenous ("bacterin") vaccines to control S. suis outbreaks is a frequent preventive measure in the field, although scientific data on immunogenicity and reduction in mortality and morbidity are scarce. The goal of our study is to experimentally evaluate the immunogenicity and protective efficacy against homologous challenge in weaned piglets of a S. suis serotype 2 bacterin-based vaccine formulated with six different commercial adjuvants (Alhydroge $\left.\right|^{\circledR}$, Emulsigen ${ }^{\circledR}-D$, Quil- $A^{\circledR}$, Montanide ${ }^{\text {TM }}$ ISA 206 VG, Montanide ${ }^{\mathrm{TM}}$ ISA 61 VG, and Montanide ${ }^{\mathrm{TM}}$ ISA 201 VG). The vaccine formulated with Montanide ${ }^{\mathrm{TM}}$ ISA 61 VG induced a significant increase in anti-S. suis antibodies, including both IgG1 and lgG2 subclasses, protected against mortality and significantly reduced morbidity and severity of clinical signs. Vaccines formulated with Montanide ISA 206 VG or Montanide ISA 201 VG also induced a significant increase in anti-S. suis antibodies and showed partial protection and reduction of clinical signs severity. Vaccines formulated with Alhydroge $\mathrm{I}^{\circledR}$, Emulsigen ${ }^{\circledR}-\mathrm{D}$, or Quil- $\mathrm{A}^{\circledR}$ induced a low and lgG1-shifted antibody response and failed to protect vaccinated piglets against a homologous challenge. In conclusion, the type of adjuvant used in the vaccine formulation significantly influenced the immune response and efficacy of the vaccine against a homologous challenge.
\end{abstract}

Keywords: Streptococcus suis, swine, bacterin vaccines, adjuvants, antibodies, Alhydroge ${ }^{\circledR}$, Emulsigen ${ }^{\circledR}-D$, Quil-A ${ }^{\circledR}$, Montanide $^{\mathrm{TM}}$

\section{Introduction}

Streptococcus suis is a Gram-positive bacterium with 29 serotypes described based on the immunogenicity of its capsular polysaccharide (CPS) [1]. It causes disease in

\footnotetext{
*Correspondence: marcelo.gottschalk@umontreal.ca; mariela. segura@umontreal.ca

Research Group On Infectious Diseases in Production Animals (GREMIP) and Swine and Poultry Infectious Diseases Research Centre (CRIPA), Faculty of Veterinary Medicine, University of Montreal, 3200 Sicotte, Saint-Hyacinthe, QC J2S 2M2, Canada
}

weaned and, occasionally, in suckling and grower piglets, with clinical signs of meningitis, arthritis, endocarditis, septicemia, and sudden death [2]. S. suis has a worldwide prevalence and it is estimated that $100 \%$ of pig farms are positive, since it is normal inhabitant of the upper respiratory tract $[3,4]$. Serotypes 2 and 9 are by far the most prevalent in Europe. In North America, serotypes 1 to 9 and 14 are usually associated to disease, being serotypes $1 / 2$ and 2 the most prevalent [ 5 , 6]. S. suis is also a zoonosis, causing mainly meningitis original author(s) and the source, provide a link to the Creative Commons licence, and indicate if changes were made. The images or other third party material in this article are included in the article's Creative Commons licence, unless indicated otherwise in a credit line to the material. If material is not included in the article's Creative Commons licence and your intended use is not permitted by statutory regulation or exceeds the permitted use, you will need to obtain permission directly from the copyright holder. To view a copy of this licence, visit http://creativecommons.org/licenses/by/4.0/. The Creative Commons Public Domain Dedication waiver (http://creativeco mmons.org/publicdomain/zero/1.0/) applies to the data made available in this article, unless otherwise stated in a credit line to the data. 
and septic shock, with high importance in certain Asian countries where raw pig products are traditionally consumed $[7,8]$. Antimicrobials are not only used to treat disease but also as prophylaxis/metaphylaxis to control S. suis in pig herds, although their use has been limited in some countries due to the increasing occurrence of antimicrobial resistance [9].

Prevention of clinical disease caused by $S$. suis is mainly based on the control of predisposal factors and the use of vaccines [10]. Since there are no universal efficacious commercial vaccines against $S$. suis infection, the use of autogenous vaccines (in general, bacterins) is widespread [11]. The production of the S. suis autogenous vaccine starts with the isolation of a specific bacterial strain(s) causing the problem in a particular farm; this bacterial isolate is then killed (generally with formalin) and formulated with a specific adjuvant [12]. The plethora of S. suis serotypes and strains, and a wide variety of adjuvants and vaccine production methods, make the evaluation of the efficacy of autogenous vaccines difficult, and often ambiguous data are acquired from field trials [11]. A recent field study showed that vaccination of piglets with a licensed autogenous vaccine composed of S. suis serotype 7 strain adjuvanted with oil-in-water adjuvant (confidential formulation) failed to induce an active immune response and clinical protection after vaccination of piglets [13]. In a vaccination study in piglets with an experimental S. suis serotype 2 bacterin, protection was recorded when formulated with a water-in-oil emulsion but not with Alhydrogel $^{\circledR}[14]$. Adjuvants are key components of a vaccine formulation and have the capacity to not only increase the vaccine-induced immune response but also modulate the type of this response and consequently the protection level obtained. Despite the importance of adjuvants, few studies have compared the effect of different adjuvants in the same experimental trial or at least under the same conditions $[14,15]$.

The goal of this study was to evaluate the influence of different commercial adjuvants included in a S. suis serotype 2 bacterin-vaccine formulation on the immunogenicity and protection against homologous challenge. This is the first controlled experimental study conducted to compare the effect of six different commercial adjuvants, widely used in animal vaccine production, on S. suis vaccine efficacy.

\section{Materials and methods}

\section{Preparation of the bacterin}

Streptococcus suis serotype 2 strain P1/7, a well-characterized virulent reference strain [16], was grown overnight onto $5 \%$ sheep blood agar plates at $37{ }^{\circ} \mathrm{C}$, and isolated colonies were cultured in $5 \mathrm{~mL}$ of Todd-Hewitt broth (THB; Becton Dickinson, Mississauga, ON, Canada) for $8 \mathrm{~h}$ at $37^{\circ} \mathrm{C}$. Then, $450 \mu \mathrm{L}$ of $1 / 1000$ dilution of 8 -h cultures were transferred into two volumes of $1.3 \mathrm{~L}$ of THB each and incubated for $16 \mathrm{~h}$ at $37^{\circ} \mathrm{C}$. Bacteria were centrifuged $10000 \times g$ for $40 \mathrm{~min}$ at $4{ }^{\circ} \mathrm{C}$, pellets were re-suspended in $250 \mathrm{~mL}$ of sterile phosphate-buffered saline (PBS) and centrifuged $10000 \times g$ for $10 \mathrm{~min}$ at $4{ }^{\circ} \mathrm{C}$. Two additional washing steps of the bacterial pellet with PBS were performed using the same centrifugation settings. After the final wash, the pellet was re-suspended in $250 \mathrm{~mL}$ of sterile PBS and the bacterial count was performed. To inactivate the bacteria, formaldehyde was added to the final concentration of $0.5 \%$ and incubated for $48 \mathrm{~h}$ at $4{ }^{\circ} \mathrm{C}$. The mixture was screened for sterility and washed three times with sterile PBS, using the same centrifugation settings. The bacterin pellet was resuspended in $250 \mathrm{~mL}$ of sterile PBS and thiomersal was added to a final concentration of $0.01 \% \mathrm{v} / \mathrm{v}$. Each immunization dose contained the equivalent to $10^{9} \mathrm{CFU} / \mathrm{mL}$.

\section{Formulation of S. suis bacterin with different adjuvants}

Six commercial adjuvants were used to make different formulations of the vaccine in this study. Vaccine formulations consisted of formalin-inactivated $10^{9} \mathrm{CFU}$ of S. suis serotype 2 strain P1/7 formulated with Alhydrogel $^{\circledR}-2 \%$ (Croda, formerly known as Brenntag Biosector A/S, InvivoGen, San Diego, CA, USA) at a final concentration of $50 \% \mathrm{v} / \mathrm{v}$ (Group 1), Emulsigen ${ }^{\circledR}$-D (MVP Adjuvants $^{\circledR}$, Phibro Animal Health Corporation, Teaneck, NJ, USA) at a final concentration of $20 \% \mathrm{v} / \mathrm{v}$ (Group 2), Quil$\mathrm{A}^{\circledR}$ (Croda) at a final concentration of $0.3 \mathrm{mg} / \mathrm{mL}$ (Group 3), Montanide ${ }^{\mathrm{TM}}$ ISA 206 VG (Group 4), Montanide ${ }^{\mathrm{TM}}$ ISA 61 VG (Group 5), and Montanide ${ }^{\text {TM }}$ ISA 201 ISA VG (Group 6) (SEPPIC, Fairfield, NJ, USA). All procedures for vaccine formulations with tested adjuvants were done according to the manufacturer's protocols. Placebo controls (corresponding adjuvant only) were included in each group. The six different commercial adjuvants were used to make vaccine formulations using the same formalin-killed bacterial suspension of S. suis serotype 2 strain P1/7.

\section{Animals}

This study was carried out in accordance with the recommendations of the guidelines and policies of the Canadian Council on Animal Care and the principles outlined in the Guide for the Care and Use of Laboratory Animals. The protocols and procedures were approved by the Animal Welfare Committee of the University of Montreal (protocol number Rech-2014). Recently weaned, three-week-old, Landrace/white mixed breed piglets were acquired from a commercial farm in Quebec, with 
no history of clinical problems caused by $S$. suis, no vaccination program against this pathogen and free of Porcine Reproductive and Respiratory Syndrome virus. All animals were probably already colonized by $S$. suis or $S$. suis-like microorganisms as they are part of the normal microbiota of the upper respiratory tract. Upon arrival, piglets were weighed, individually tagged, assigned to two groups (placebo or vaccinated; $n=10$ per group) with equal average weight (approximately $5-6 \mathrm{~kg}$ ), and placed in the Level II experimental animal facility of the Faculty of Veterinary Medicine, University of Montreal. Piglets were fed commercial, pelleted non-medicated food, with an addition of dry veggie supplements. The same procedure was performed for all 6 adjuvant groups of piglets for a total of 120 piglets.

\section{Experimental design: immunization and challenge of pigs}

Two days upon arrival, piglets were immunized intramuscularly (IM) in the neck muscle, with $1 \mathrm{~mL}$ of formalin-killed S. suis serotype 2 strain P1/7 with selected adjuvant (vaccine group) or adjuvant only in PBS (placebo control group). The second dose of vaccine and placebo were administered IM two weeks after the first dose (Additional file 1). Twelve days after the second injection, the immunized and control animals were weighed, sedated using a dose of $0.5 \mathrm{mg} / \mathrm{kg}$ Atravet (Boehringer Ingelheim, Burlington, ON, Canada), and challenged with an intraperitoneal (IP) injection of $5 \mathrm{~mL}\left(5 \times 10^{9} \mathrm{CFU}\right)$ of a log-phase culture of $S$. suis serotype 2 strain P1/7. The average weight of the piglets on the day of the challenge was $14 \mathrm{~kg}$. Blood samples were collected from the jugular vein before each immunization and before challenge for the determination of antibody responses (see below). Following the challenge, pigs were monitored three times per day over a period of nine days for the presence of clinical signs and mortality. The individuals observing the animals were blinded to the treatments. A daily clinical score was calculated based on a clinical observation sheet. Assessed were general behavior, locomotion (musculoskeletal alterations) and functional alteration of the central nervous system (CNS). Behavior clinical scores were given as follows: $0=$ normal attitude and response to stimuli; $1=$ slight depression with marginally delay in the response to the stimuli, but preserved appetite; $2=$ moderate depression, animal only responds to repeated stimuli, reluctant to move, decreased appetite; $3=$ severe depression, non-responsive, recumbent, incoordination, diminished appetite. Locomotion clinical scores were given as follows: $0=$ normal gait and posture; $1=$ one joint affected, light lameness, but rises and moves without assistance; $2=$ moderate lameness, 2-3 joints affected with the swelling but stands without assistance; $3=$ severe lameness, ataxia $3-4$ joints affected, recumbent and cannot stand or move. Finally, central nervous system (CNS) clinical scores were given as follows: $0=$ normal physiological behavior and response to stimuli; $1=$ slight incoordination, strabismus; $2=\bmod$ erate incoordination, trembling; $3=$ sever, lateral or dorsal head inclination, ataxia, opisthotonus, nystagmus, convulsions. Pigs having a clinical score $=3$ in either category and a body temperature above $40{ }^{\circ} \mathrm{C}$ for two consecutive days were humanely euthanized. Ketamine $\left(20 \mathrm{mg} / \mathrm{kg}\right.$; Narketan ${ }^{\circledR}$, Vetoquinol, Lavaltrie, QC, Canada) and xylazine $\left(2 \mathrm{mg} / \mathrm{kg}\right.$; Rompun ${ }^{\circledR}$, Bayer, Mississauga ON, Canada) were administered IM to achieve complete anesthesia followed by intracardiac administration of pentobarbital sodium $\left(100 \mathrm{mg} / \mathrm{kg}\right.$; Euthanyl ${ }^{\circledR}$, Vetoquinol). Blood was collected from each piglet before euthanasia for bacteriological analyses. A post-mortem examination procedure was conducted for all pigs. Swabs were collected from meninges and synovial fluid from affected joint cavities and seeded on blood agar for bacterial recovery. Samples of liver and spleen were collected and cultured for bacterial recovery. The individuals performing the necropsies and bacterial recovery were blinded to the treatments. Samples for bacterial isolation and serotyping were taken from all euthanized animals as well as survival animals at the end of the trial.

\section{Measurement of antibodies against $S$. suis serotype 2 and CPS}

Blood was aseptically collected from the jugular vein at three time points: before the first dose (day 0), before the second dose (day 14), and before the challenge (day 26). Blood was centrifuged $3000 \times g$ for $10 \mathrm{~min}$, and sera were collected and stored at $-20{ }^{\circ} \mathrm{C}$ until further analysis. Sera from vaccinated and control piglets were analyzed by an indirect ELISA for antibodies against whole $S$. suis bacteria, standardized using the challenge strain, as previously reported [13]. Briefly, Polysorb plates (NuncImmuno; Thermo Scientific, Mississauga, ON, Canada) were coated with $100 \mu \mathrm{L} /$ well of a suspension equivalent to $10^{8} \mathrm{CFU} / \mathrm{mL}$ S. suis serotype 2 strain $\mathrm{P} 1 / 7$ in $\mathrm{dd}_{2} \mathrm{O}$. Plates were air-dried for two days at room temperature (RT) and finally fixed with $50 \mu \mathrm{L} /$ well of $100 \%$ methanol. After evaporation of methanol, plates were stored at RT until use. For ELISA, plates were washed with PBS-tween (PBS-T) containing 0.05\% Tween-20 and blocked with 2\% skim milk for $1 \mathrm{~h}$ at RT. To establish the antibody titers, pig sera were serially diluted (twofold) in PBS-T (starting with a dilution of $1 / 200$ ) and incubated for $1 \mathrm{~h}$ at RT. For titration of pig total Ig $[\operatorname{IgM}+\operatorname{IgG}]$ or IgM, plates were incubated with peroxidase-conjugated goat anti-pig total Ig [IgM + IgG] (Jackson ImmunoResearch, West Grove, PA, USA) or IgM (BioRad, Hercules, CA, USA) antibodies for $1 \mathrm{~h}$ at RT. For porcine IgG1 or IgG2 detection, 
mouse anti-porcine IgG1 or IgG2 (BioRad) was added for $1 \mathrm{~h}$ at RT. After washing, peroxidase-conjugated goat anti-mouse IgG (Jackson ImmunoResearch) was added for $1 \mathrm{~h}$ at RT. Plates were developed with 3,3',5,5'-tetramethylbenzidine (TMB; Invitrogen, Burlington, ON, Canada) substrate, and the enzyme reaction was stopped by the addition of $0.5 \mathrm{M} \mathrm{H}_{2} \mathrm{SO}_{4}$. Absorbance was read at $450 \mathrm{~nm}$ with an ELISA plate reader. The reciprocal of the last serum dilution that resulted in an optical density at $450 \mathrm{~nm}\left(\mathrm{OD}_{450}\right)$ of $\leq 0.2$ (cutoff) was considered the titer of that serum. To control inter-plate variations, an internal reference positive control was added to each plate [13]. Reaction in TMB was stopped when an $\mathrm{OD}_{450}$ of 1.0 was obtained for the positive internal control. Optimal dilutions of the positive internal control sera and antiporcine antibodies or conjugates were determined during preliminary standardizations.

For selected time points, to measure anti-CPS specific antibodies, a previously developed protocol was applied [17] using native S. suis serotype 2 CPS purified as described [18]. Serum antibody titers were determined as described above.

\section{Statistical analysis}

ELISA data were log-10 transformed to normalize distributions. Unless otherwise specified, a linear mixed model was used with sampling time as the within-subject fixed effect, group (vaccinated or placebo) as the betweensubject fixed effect and animal identification (id) as a random effect. Piglet id was used for serology analyses. The model also took into account unequal variances in the two groups. A priori contrasts was performed to compare pairs of means adjusting the alpha level downward for each comparison with the sequential BenjaminiHochberg procedure. In the analysis of IgG1 and IgG2 subclasses or anti-CPS antibodies in piglet sera, an equal variance $t$-test was used to compare means according to status. Survival rates were evaluated with chi-square analysis using the Kaplan-Meier method, and the significance of the difference was tested using the log-rank test. The clinical scores were transferred by ranking, and the significance of the difference between groups was determined by the $t$-test. Statistical analyses and graphing were performed using GraphPad Prism 8 software (GraphPad Software, San Diego, CA, USA). The level of statistical significance was set at 0.05 .

\section{Results}

\section{Survival rates and clinical signs}

The goal of our study was to compare the immunogenicity and protection of bacterin vaccines formulated with 6 different commercial adjuvants: an aluminum hydroxide gel (Alhydrogel $\left.{ }^{\circledR}\right)$; an oil-in-water $(\mathrm{O} / \mathrm{W}) /$ nanoparticle dual adjuvant emulsion (Emulsigen ${ }^{\circledR}-\mathrm{D}$ ); a saponin (Quil$\left.\mathrm{A}^{\circledR}\right)$; a water-in-oil-in-water $(\mathrm{W} / \mathrm{O} / \mathrm{W})$ mineral oil-based adjuvant emulsion (Montanide ${ }^{\mathrm{TM}}$ ISA $206 \mathrm{VG}$ ); a waterin-oil (W/O) mineral oil-based adjuvant emulsion (Montanide $^{\mathrm{TM}}$ ISA $61 \mathrm{VG}$ ); and a $\mathrm{W} / \mathrm{O} / \mathrm{W}$ mineral oil-based adjuvant emulsion (Montanide ${ }^{\mathrm{TM}}$ ISA 201 ISA). Results obtained for each vaccine formulation were compared to the corresponding placebos, prepared with the same adjuvant.

The IP challenge model used in this study was able to reproduce typical clinical signs and lesions caused by $S$. suis infection in weaned piglets as those observed in the field (Additional file 2) [2]. Challenged animals showed signs of depression, incoordination, and shifting lameness (Additional file 2B). In more severe cases, there were signs of septicemia and meningitis, characterized by convulsion, head inclination, ataxia, opisthotonos, paddling, and nystagmus (Additional file 2A). Necropsy revealed typical polyarthritis lesions with abundant fibrinopurulent exudate in joint cavities (Additional file 2C). Spleen was enlarged, with petechial hemorrhages indicating systemic infection (septicemia). The IP challenge model was able to produce consistent mortality and morbidity in all six experimental placebo groups (Figures 1, 2, 3).

Animals immunized with vaccines formulated with Alhydrogel ${ }^{\circledR}$ (survival rate of $40 \%$ ), with Emulsigen ${ }^{\circledR}$-D (survival rate of $33 \%$ ) or with Quil- $\mathrm{A}^{\circledR}$ (survival rate of $40 \%$ ) presented survival rates and clinical scores of locomotion, CNS, and behavior similar to those observed in corresponding placebos (Figures $1 \mathrm{~A}-\mathrm{C}, 2 \mathrm{~A}-\mathrm{C}$ ). Indeed, morbidity was high in both vaccinated and placebo animals for these three adjuvant groups. Clinical signs of locomotion in a form of limping, swollen joints, and difficulties in moving, were observed in 90 to $100 \%$ of Alhydrogel ${ }^{\circledR}$, Emulsigen ${ }^{\circledR}$-D, and Quil- ${ }^{\circledR}$ vaccinated piglets (Table 1). CNS clinical signs were observed in 60 to $80 \%$ of vaccinated piglets in these three adjuvant groups (Table 1) with no statistical differences between vaccinated and placebo animals. Besides, there was no statistical difference amongst these three vaccine formulations in any of the clinical sign categories (Figure 4A). Furthermore, S. suis was isolated from the blood, synovial fluid, and organs of vaccinated piglets at a similar rate to that of placebo animals (Table 1).

The survival rate of piglets vaccinated with Montanide $^{\mathrm{TM}}$ ISA 201 or 206 VG was $60 \%$, and although the survival rates of the corresponding placebo groups were $40 \%$ and $30 \%$, respectively, the difference was not statistically significant (Figures 1D, F). An improvement in clinical scores was observed for both vaccinated groups compared to corresponding placebos but, as in the case of mortality, there was no statistical difference during nine 

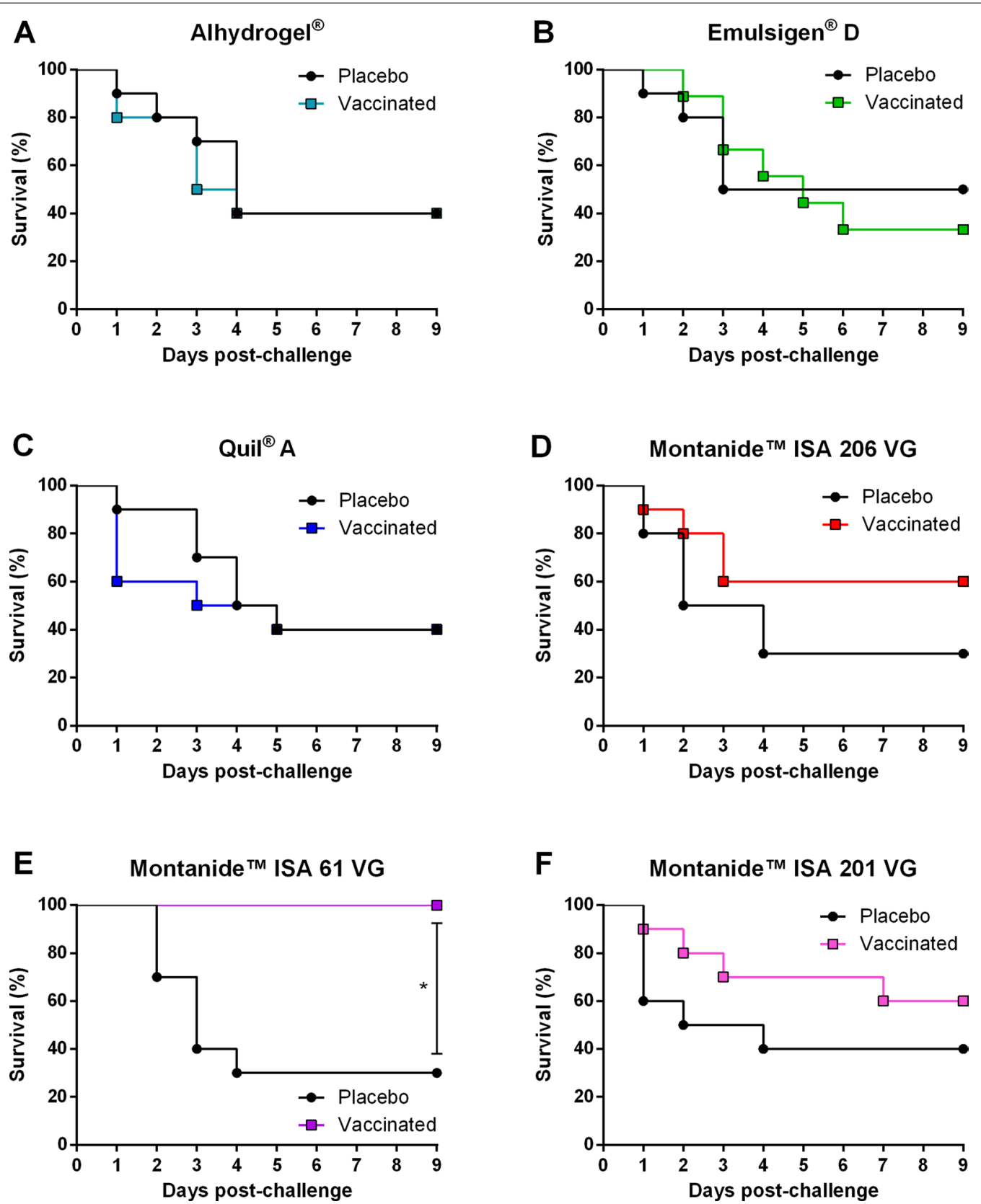

Figure 1 Kaplan-Maier survival rate curves. Piglets were vaccinated with the equivalent to $10^{9} \mathrm{CFU} / \mathrm{mL}$ of S. suis strain P1/7 bacterin formulated either with Alhydroge $\left.\right|^{\circledR}(\mathbf{A})$, Emulsigen ${ }^{\circledR}-\mathrm{D}(\mathbf{B})$, Quil-A ${ }^{\circledR}(\mathbf{C})$, Montanide ${ }^{\mathrm{TM}}$ ISA $206 \mathrm{VG}(\mathbf{D})$, Montanide ${ }^{\mathrm{TM}}$ ISA 61 VG (E), or Montanide ${ }^{\mathrm{TM}}$ ISA 201 VG (F). All piglets were challenged intraperitoneally with $5 \times 10^{9} \mathrm{CFU}$ of $\mathrm{S}$. suis strain P1/7. Each vaccine formulation group of vaccinated piglets $(n=10)$ had a corresponding placebo group of piglets $(n=10)$ challenged at the same time. The clinical signs observations were conducted three times per day, nine days post-infection. ${ }^{*}, P<0.05$.

days (Figures 3A, C). S. suis was isolated in 6 out of 10 vaccinated piglets in the Montanide ${ }^{\mathrm{TM}}$ ISA 206 VG group, which is an improvement compared to 9 out of 10 animals in Montanide ${ }^{\mathrm{TM}}$ ISA 201 VG group (Table 1).

The survival rate of piglets vaccinated with Montanide $^{\mathrm{TM}}$ ISA 61 VG was $100 \%$, which was significantly different compared to the corresponding placebo with a survival rate of $30 \%$ (Figure 1E). Furthermore, clinical scores in all categories were significantly lower in the vaccinated group compared to the placebo group (Figure 3B). The vaccinated group did not have a single case of meningitis while the placebo group had 7 out of 10 


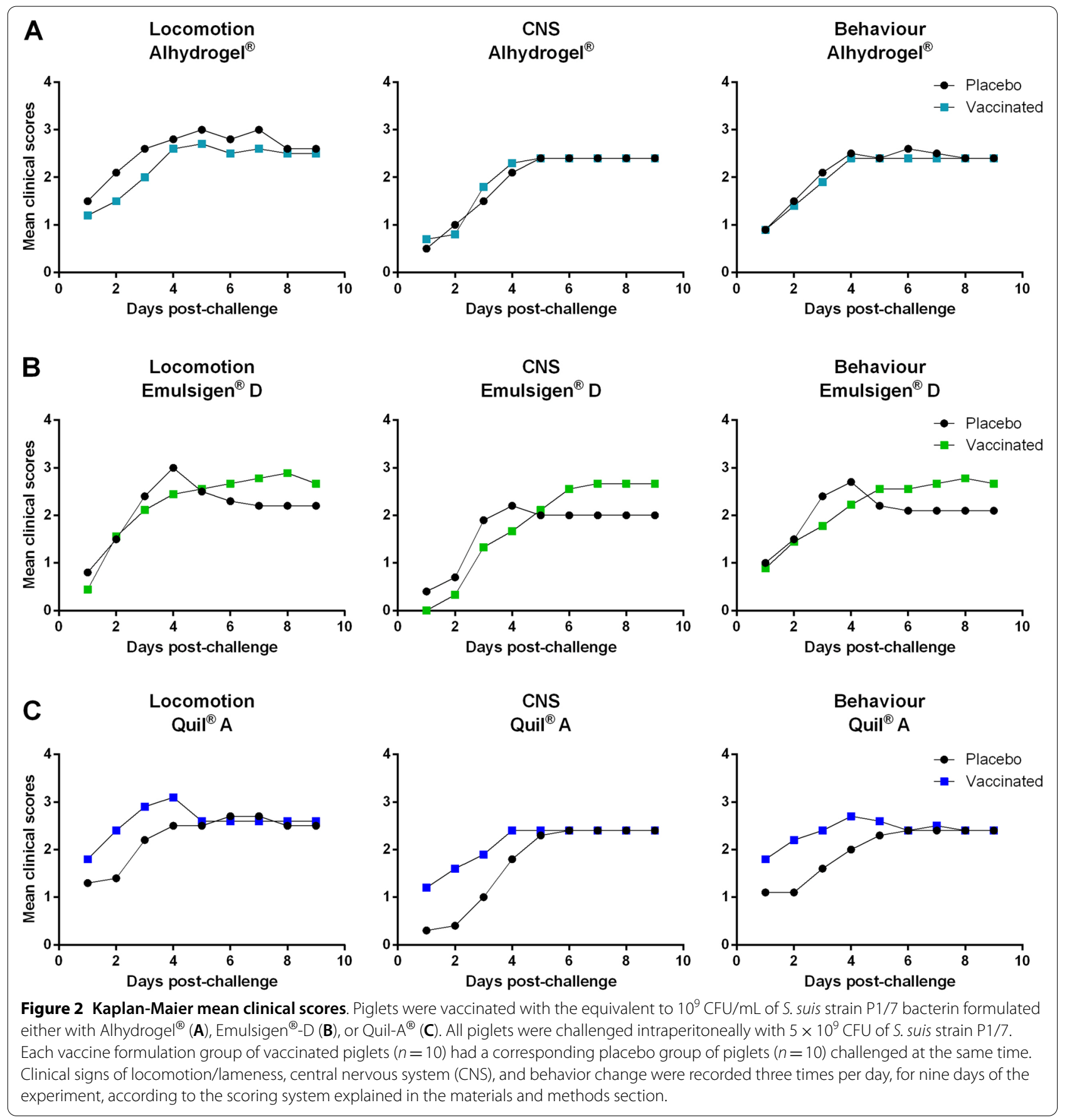

animals with aggravated CNS clinical signs (Table 1). Although 7 out of 10 vaccinated animals showed clinical signs of lameness, swollen joints, and limping, the overall clinical score was low, the clinical signs were mild, and all animals were able to recover completely until the end of the trial. Only 3 out of 10 vaccinated animals had $S$. suis isolated from the joints or organs, with no isolation from the brain or blood. Opposite, $S$. suis was isolated from the joints, tissue samples, and/ or blood of the majority of placebo piglets (Table 1). Finally, clinical sign scores were significantly decreased in Montanide ${ }^{\mathrm{TM}}$ ISA $61 \mathrm{VG}$ vaccine group compared to the other two Montanide ${ }^{\mathrm{TM}}$ formulations (Figure 4B).

\section{Immunogenicity against $S$. suis serotype $\mathbf{2}$}

ELISA analyses of total Ig [IgM + IgG] antibody titers against $S$. suis serotype 2 after immunization revealed different levels of immunogenicity induced by the 


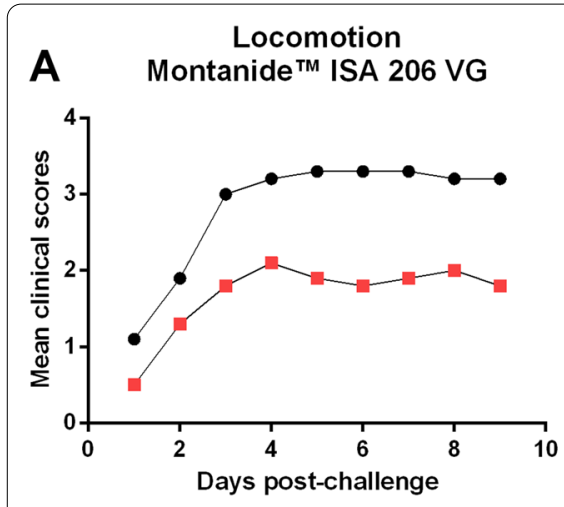

B $\quad \begin{aligned} & \text { Locomotion } \\ & \text { Montanide }\end{aligned}$

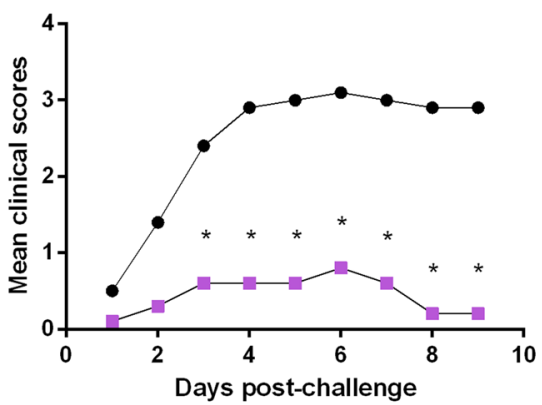

Locomotion

C Montanide ${ }^{\text {TM }}$ ISA 201 VG

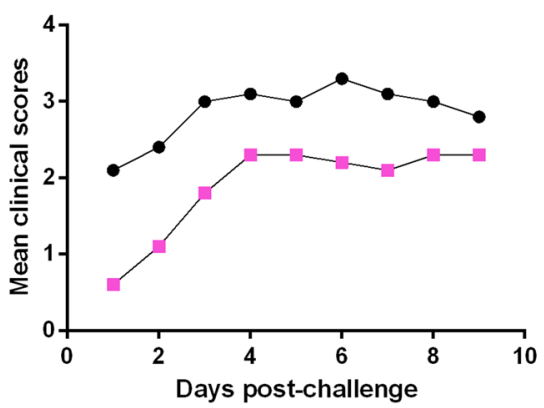

CNS

Montanide $^{\mathrm{TM}}$ ISA 206 VG

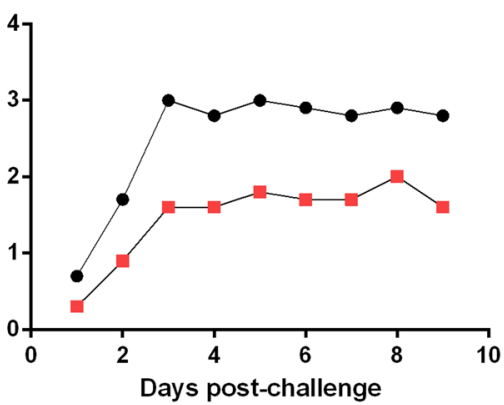

CNS

Montanide $^{\mathrm{TM}}$ ISA 61 VG

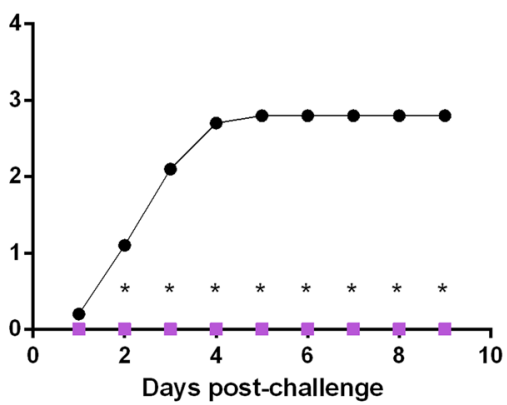

CNS

Montanide $^{\mathrm{TM}}$ ISA 201 VG

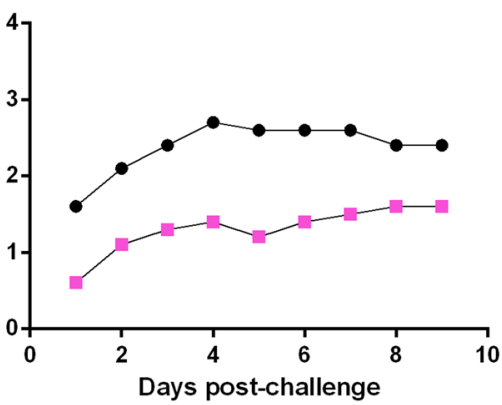

Behaviour

Montanide $^{\text {TM }}$ ISA 206 VG

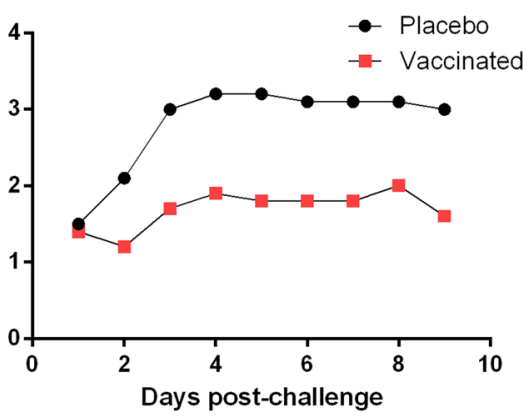

Behaviour Montanide $^{\mathrm{TM}}$ ISA 61 VG

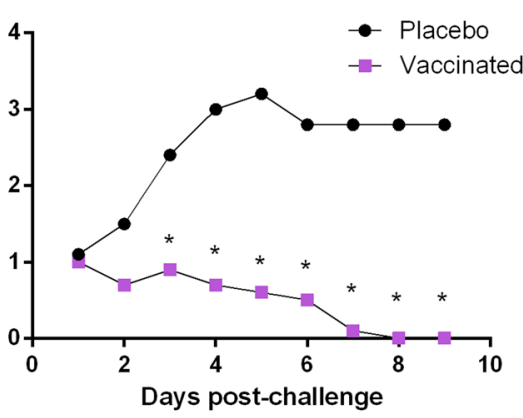

Behaviour

Montanide $^{\mathrm{TM}}$ ISA 201 VG

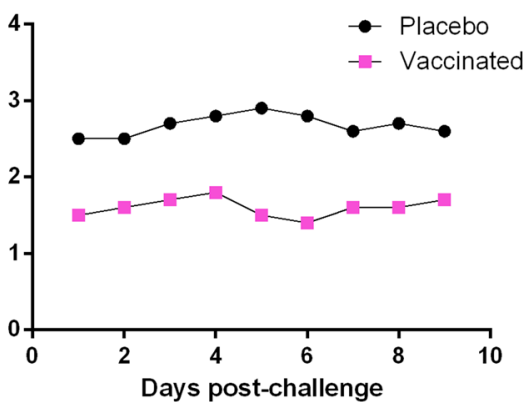

Figure 3 Kaplan-Maier mean clinical scores. Piglets were vaccinated with the equivalent to $10^{9} \mathrm{CFU} / \mathrm{mL}$ of S. suis strain P1/7 bacterin formulated with either Montanide ${ }^{\mathrm{TM}}$ ISA 206 VG (A), Montanide ${ }^{\mathrm{TM}}$ ISA 61 VG (B), or Montanide ${ }^{\mathrm{TM}}$ ISA 201 VG (C). All piglets were challenged intraperitoneally with $5 \times 10^{9} \mathrm{CFU}$ of S. suis strain P1/7. Each vaccine formulation group of vaccinated piglets $(n=10)$ had a corresponding placebo group of piglets $(n=10)$ challenged at the same time. Clinical signs of locomotion/lameness, central nervous system (CNS), and behavior change were recorded three times per day, for nine days of the experiment, according to the scoring system explained in the materials and methods section. ${ }^{*}, P<0.05$.

vaccine formulations. Upon arrival, all piglets had high basal levels of total Ig [IgM+IgG] antibody titers as detected using whole $S$. suis serotype 2 antigen, which suggests the presence of maternal antibodies acquired during the suckling period (Figure 5). These antibody levels decreased over time in all placebo groups, reaching the lowest level at 7 weeks of age (Figure $5 ; P<0.001$ vs. 3 weeks of age). Furthermore, at five weeks of age (after the $1^{\text {st }}$ vaccine dose), none of the vaccine formulations was able to increase the antibody titers compared to the corresponding placebos (Figure 5). Indeed, a significant increase in anti-S. suis antibody levels were only observed after the $2^{\text {nd }}$ vaccine dose for all vaccine formulations (Figures 5B-F), except for that adjuvanted with Alhydrogel $^{\circledR}$ (Figure 5A). In addition, the latter vaccine formulation did not induce antibody isotype switching, 
Table 1 Summary of the number of piglets with clinical signs and S. suis isolation.

\begin{tabular}{|c|c|c|c|c|}
\hline & Locomotion & $\begin{array}{l}\text { CNS/other severe clinical } \\
\text { signs }\end{array}$ & S. suis in blood & $\begin{array}{l}\text { Total } \\
\text { S. suis } \\
\text { isolation }\end{array}$ \\
\hline \multicolumn{5}{|c|}{ Group 1, Alhydroge ${ }^{\circledR}$} \\
\hline Vaccine & $8 / 9^{a}$ & $6 / 10$ & $6 / 8^{b}$ & $8 / 10$ \\
\hline Placebo & $10 / 10$ & $6 / 10$ & $5 / 8^{b}$ & $9 / 10$ \\
\hline \multicolumn{5}{|c|}{ Group 2, Emulsigen ${ }^{\circledR}-D$} \\
\hline Vaccine & $8 / 9^{c}$ & $7 / 9^{c}$ & $7 / 9^{c}$ & $7 / 9^{c}$ \\
\hline Placebo & $9 / 9^{a}$ & $7 / 10$ & $8 / 9^{b}$ & $9 / 10$ \\
\hline \multicolumn{5}{|c|}{ Group 3, Quil-A ${ }^{\circledR}$} \\
\hline Vaccine & $10 / 10$ & $8 / 10$ & $5 / 10$ & $10 / 10$ \\
\hline Placebo & $10 / 10$ & $6 / 10$ & $5 / 10$ & $8 / 10$ \\
\hline \multicolumn{5}{|c|}{ Group 4, Montanide ${ }^{\mathrm{TM}}$ ISA 206} \\
\hline Vaccine & $7 / 10$ & $6 / 10$ & $4 / 10$ & $6 / 10$ \\
\hline Placebo & $9 / 9^{a}$ & $9 / 10$ & $7 / 9^{b}$ & $9 / 10$ \\
\hline \multicolumn{5}{|c|}{ Group 5, Montanide ${ }^{\mathrm{TM}}$ ISA 61} \\
\hline Vaccine & $7 / 10$ & $0 / 10$ & $0 / 10$ & $3 / 10$ \\
\hline Placebo & $10 / 10$ & $7 / 10$ & $7 / 10$ & $9 / 10$ \\
\hline \multicolumn{5}{|c|}{ Group 6, Montanide ISA 201} \\
\hline Vaccine & $8 / 9^{a}$ & $4 / 10$ & $2 / 9^{b}$ & $9 / 10$ \\
\hline Placebo & $7 / 7^{\mathrm{a}}$ & $7 / 10$ & $2 / 7^{b}$ & $10 / 10$ \\
\hline
\end{tabular}

a Piglets died at Day 1 thus locomotion signs could not be collected.

b Blood could not be collected from one or more animals.

c One piglet in the vaccine group died before the second vaccination due to causes not related to the S. suis infection.

since there was no difference in IgM, IgG1, and IgG2 antibody titers between Alhydrogel ${ }^{\circledR}$ placebo and vaccine group at seven weeks of age (Figure 6A).

Emulsigen ${ }^{\circledR}-D$ and Quil- $A^{\circledR}$ vaccine formulations induced a significant increase in total $\operatorname{Ig}[\operatorname{IgM}+\operatorname{IgG}]$ antibody titers at seven weeks of age, after the $2^{\text {nd }}$ vaccine dose (Figures $5 \mathrm{~B}, \mathrm{C}$ ). When analyzing the antibody profile (Figure 6B), it was observed that Emulsigen ${ }^{\circledR}-\mathrm{D}$ vaccine formulation induces an increase in IgG1 $(P=0.001)$ and, to a lesser extent of IgG2 $(P=0.01)$ against $S$. suis serotype 2 . On the other hand, Quil- $\mathrm{A}^{\circledR}$ vaccine formulation induced isotype switching towards IgG1 only $(P=0.005$; Figure $6 \mathrm{C})$.

All three Montanide ${ }^{\mathrm{TM}}$ vaccine formulations were able to induce a significant increase in total $\operatorname{Ig}[\operatorname{IgM}+\operatorname{IgG}]$ antibody titers against $S$. suis serotype 2 at seven weeks of age, after the $2^{\text {nd }}$ vaccine dose (Figure $5 \mathrm{D}-\mathrm{F}$ ). The highest increase in antibody titers was observed in pigs vaccinated with the vaccine formulated Montanide ${ }^{\mathrm{TM}}$ ISA 61 VG (Figure 5E). In terms of the isotype profile of induced antibodies, a significant and marked increase in both, IgG1 and IgG2 subclasses was observed in animals immunized with the three Montanide ${ }^{\mathrm{TM}}$ vaccine formulations (Figure 7).

\section{Immunogenicity against $S$. suis CPS}

Antibodies directed against the CPS of S. suis are known to be usually low but important for protection [17]. In the current study, sera from vaccinated piglets at seven weeks of age were tested to determine the effect of different vaccine formulations on the induction of CPSspecific antibodies. There was no significant increase in anti-CPS antibodies in animals immunized with none of the vaccine formulations (Figure 8).

\section{Discussion}

Adjuvants are key components of vaccine formulations and possess multiple properties able to increase the level (magnitude) of the vaccine-induced immunological response, reduce the number of doses, control the release of the antigen (depot effect) at the site of the injection and, importantly, to modulate the type of induced immunity. The latter effect may have a major impact on the vaccine-induced protection against clinical disease [19].

Facing both the lack of effective commercial vaccines and the forthcoming restrictions in the prophylactic and metaphylactic use of antimicrobials, swine producers have increased the use of autogenous vaccines (bacterins) to prevent and control S. suis outbreaks. Nevertheless, as 


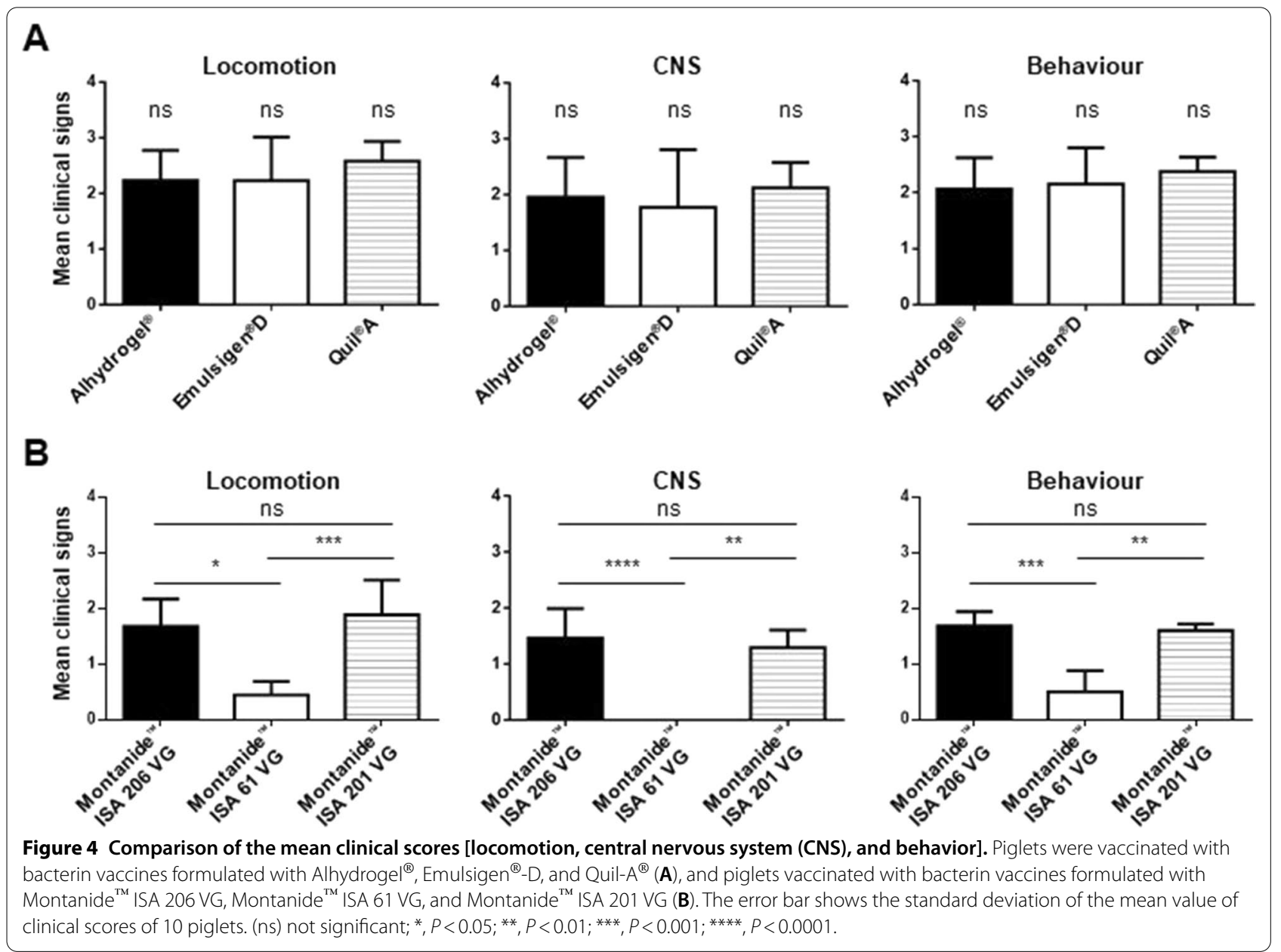

recently reviewed by Rieckmann et al. [11], there is a lack of scientific data on the actual efficacy of this type of vaccine and the immune response induced in vaccinated animals. Furthermore, only two studies have comparatively addressed the role of different adjuvants on the antibody response and/or protection induced by a $S$. suis bacterin vaccination $[14,15]$. In the present work, we compared six commercial and widely used veterinary adjuvants under the same experimental conditions.

Experimental infections using virulent $S$. suis strains are not easy to reproduce [20]. In fact, presence of serious clinical signs in the field are frequently associated to co-factors, which are usually absent in research animal facilities [10]. Indeed, when using the more natural intranasal route of infection with conventional animals, the success rate on reproducing the disease is usually very low (unpublished observations). In fact, almost all animals are colonized by S. suis or S. suis-like microorganisms and it is not possible to find conventional animals "free of S. suis". Caesarian-derived colostrum-deprived germ-free piglets are highly susceptible [20], but they do not represent the reality of conventional animals. Vaccination of piglets against $S$. suis aims to increase antibodymediated bacterial killing in blood to prevent septicemia. Our systemic challenge model, using an intraperitoneal route of infection, showed high reproducibility and consistency of clinical results which is of the utmost importance when comparing the effect of adjuvants on a given vaccine formulation $[20,21]$. Overall, results showed that the type of adjuvant used in the vaccine formulation has a paramount effect on the protection of piglets against $S$. suis challenge.

Maternal antibodies are known to interfere with the vaccine capacity to induce optimal immune responses, as previously recorded in immunization studies for other bacterial diseases common in piglets [22]. Vaccine interference with maternal antibodies has specifically been suggested for S. suis [23]. As previously reported, piglets used in the current study possessed maternal antibodies, since most sows are colonized by S. suis (or S. suis-like microorganisms) and normally possess high levels of antibodies [13, 23, 25]. High basal 
A

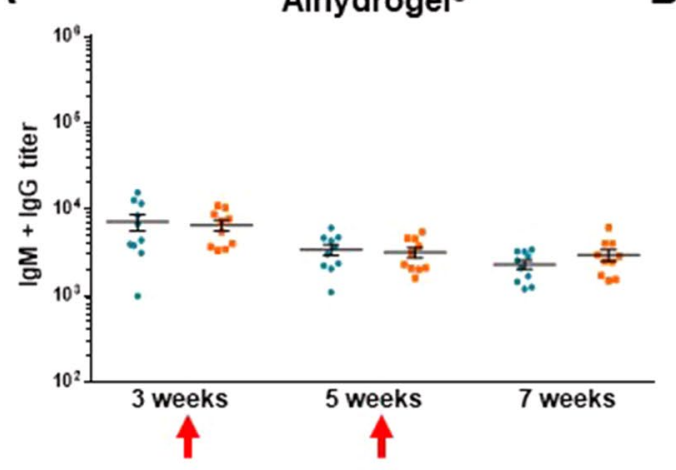

B

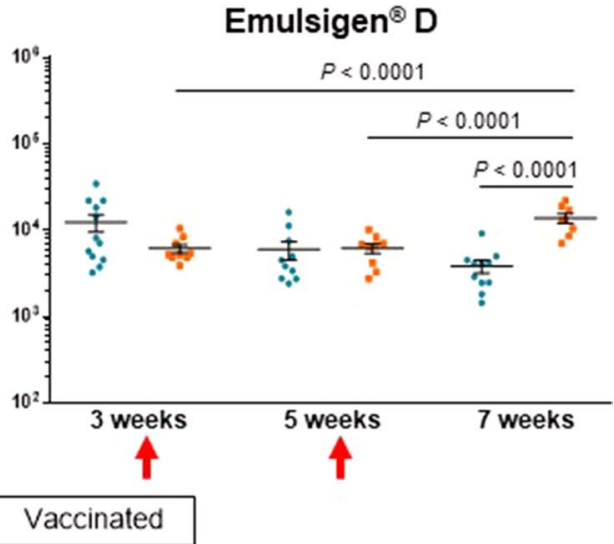

C

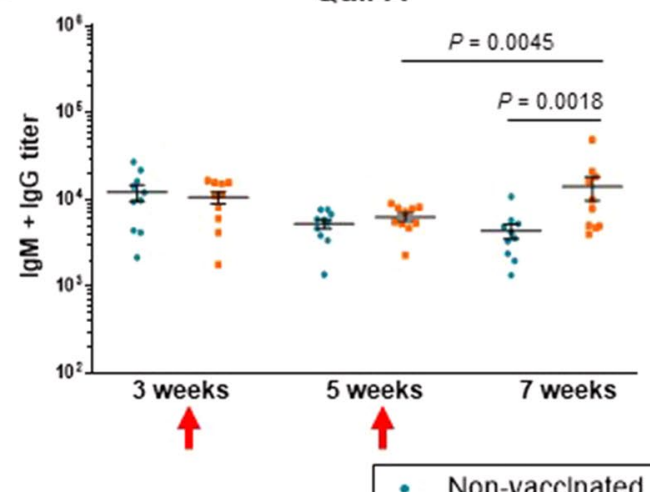

D

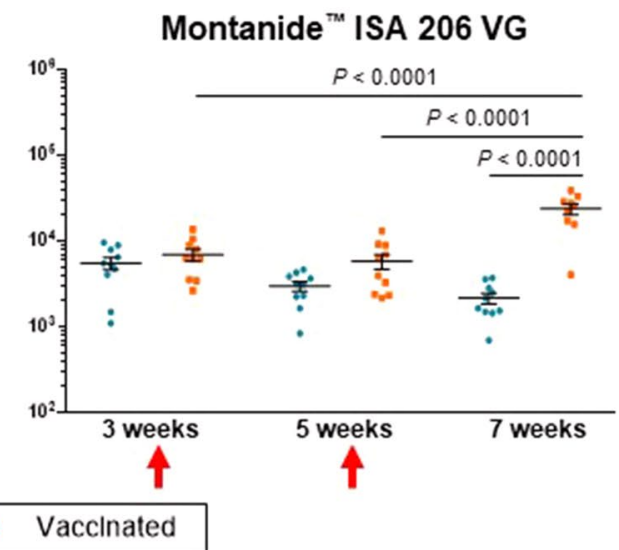

E

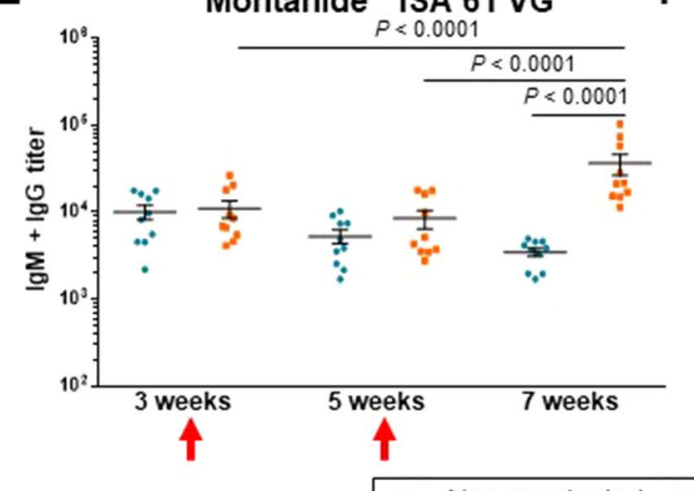

F

Montanide ISA 201 VG

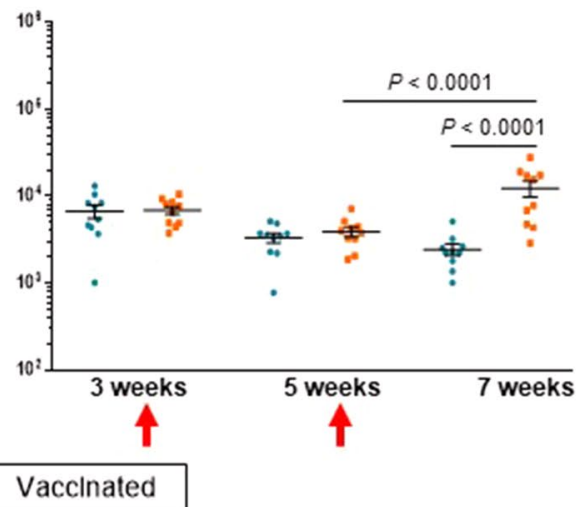

Figure $\mathbf{5}$ Total $\mathbf{l g}[\mathbf{l g} \mathbf{M}+\mathbf{l g} \mathbf{g}]$ levels against $\mathbf{S}$. suis serotype $\mathbf{2}$ in piglets as determined by ELISA. Piglets were vaccinated with the equivalent to $10^{9} \mathrm{CFU} / \mathrm{mL}$ of S. suis strain P1/7 bacterin formulated either with Alhydrogel ${ }^{\circledR}(\mathbf{A})$, Emulsigen ${ }^{\circledR}$-D (B), Quil-A ${ }^{\circledR}$ (C), Montanide ${ }^{\mathrm{TM}}$ ISA 206 VG (D), Montanide ${ }^{\text {TM }}$ ISA 61 VG (E), or Montanide ${ }^{\text {TM }}$ ISA 201 VG (F). The $1^{\text {st }}$ dose was given at 3 weeks of age and the $2^{\text {nd }}$ dose at 5 weeks of age (red arrows). Each vaccine formulation group of vaccinated piglets $(n=10)$ had a corresponding placebo group of piglets ( $n=10)$. Antibody titers for individual piglets are shown with horizontal bars representing mean \pm SEM. Values significantly different are shown in the graph with the corresponding P-value. 


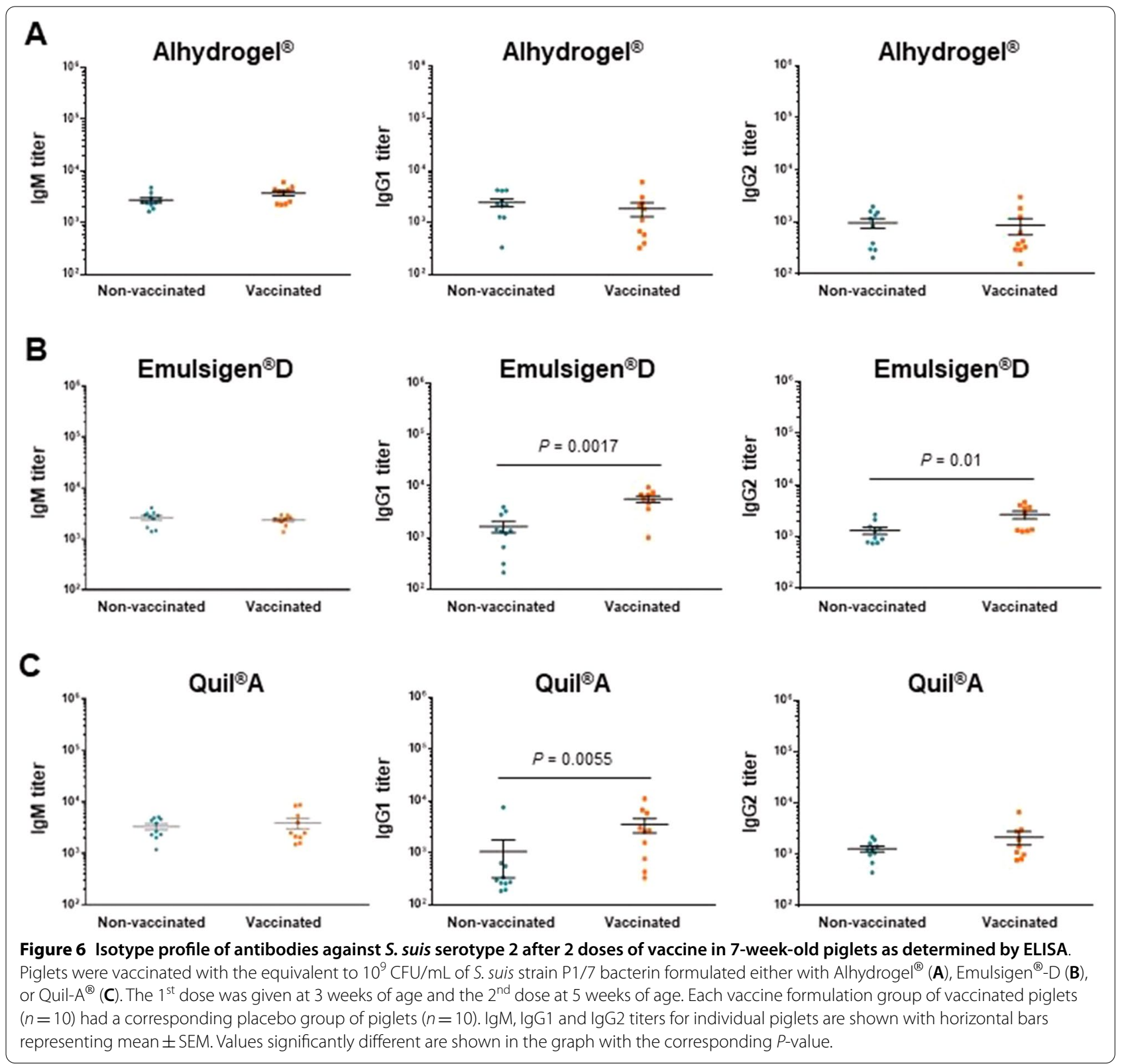

levels of maternal antibodies reacting with whole bacteria of S. suis serotype 2 were still present at weaning, which might explain the fact that one-dose immunization was not sufficient to induce a significant increase in specific anti-S. suis antibodies in vaccinated piglets and this independently of the adjuvant used. However, this hypothesis should still be confirmed. In the field, it is not unusual to give the first dose of vaccine at processing during the first week of life [13]. In the current study, even if the first dose of the vaccine was administered at weaning (three weeks of age), the effect was only observed after the $2^{\text {nd }}$ vaccine dose. The exact origin of maternal antibodies in the current study (as well as those from other studies) are unknown. In fact, the herd of origin of the animals used in this study did not have clinical signs due to $S$. suis in weaned piglets. Indeed, since whole bacteria was used as antigen for the ELISA test, it is highly possible that cross-reacting antibodies are detected. These antibodies might have been generated in adult animals by $S$. suis strains that are part of the normal microbiota or even by other $S$. suis-like microorganisms that are present in the upper respiratory tract $[3,24]$. Adult animals usually present high levels of antibodies tested for any serotype 


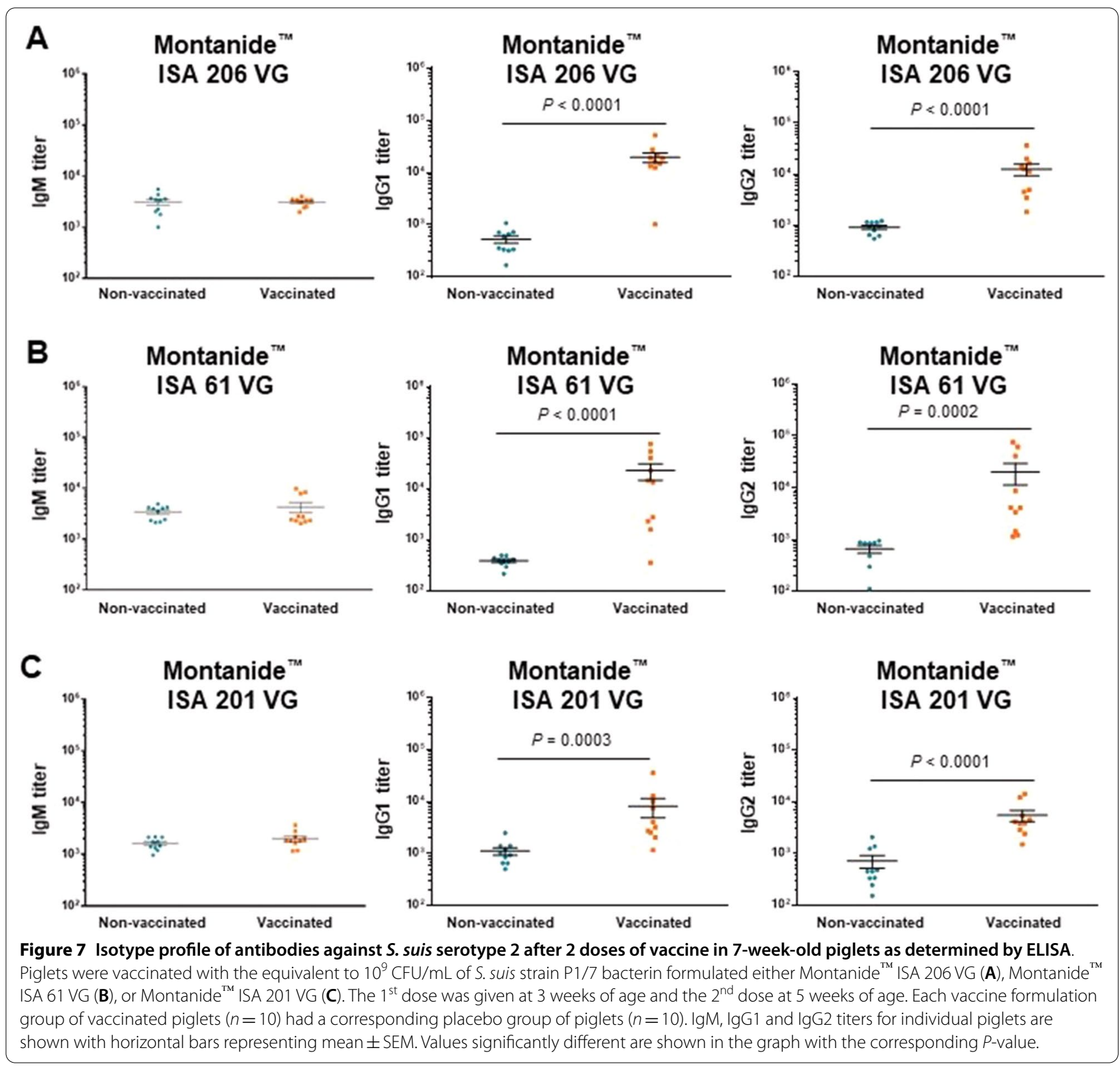

of S. suis [13, 25] (unpublished observations), which may explain why $S$. suis-associated diseases are almost never observed in older animals [10]. Finally, in addition to the presence of some residual maternal antibody interference, other features that might also explain the lack of immunological response after one vaccine dose include an immature immune system, diet change, and other stressing factors [26, 27]. Finally, the type of antigen (S. suis whole encapsulated bacteria) might not be immunogenic enough to support a one-dose vaccination program.
The results of this study were able to confirm previous findings on the limited or lack of immunogenicity and/or protection of bacterin vaccines adjuvanted with aluminum hydroxide $[14,28]$. This adjuvant, commonly known as alum, has been one of the most extensively used aluminum salts as an adjuvant for swine vaccines so far. It can form a short-term depot and is inexpensive, safe and simple to formulate [19]. Although it has been used for over 90 years in human and animal vaccines, there are still unknowns about the mechanisms of immune stimulation [29]. Nevertheless, our data indicate 


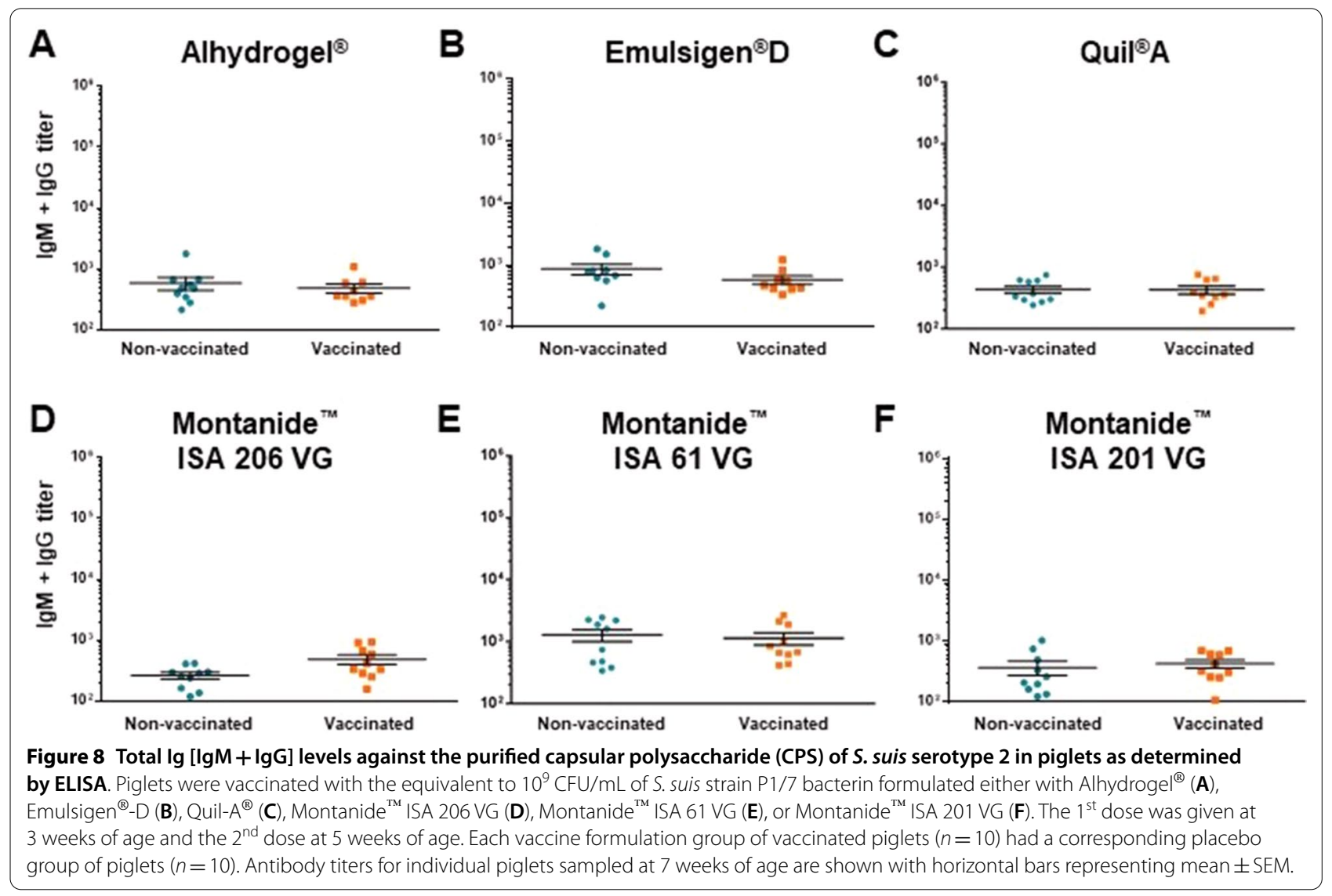

that there is no scientific rationale to use aluminum hydroxide in S. suis bacterin vaccine formulations due to the low immunogenicity and lack of protection in weaned piglets against S. suis serotype 2 experimental infection. Since the antigen can also influence the adjuvant effect and appropriate formulation, more research on the use of aluminum adjuvants for $S$. suis vaccines in swine would be required $[21,30]$.

As aforementioned, adjuvants have the potential to modulate the features of the antibody response induced by the vaccine. Indeed, the protection ability of the diverse Ig classes and subclasses depends on the specificity and affinity with the targeted antigen and their biological functions. In mice, IgG2b, IgG2c, and IgG3 are considered "type 1 IgG subclasses" because they are associated with IFN- $\gamma$-dominant Th1 immune responses and are particularly effective at favoring bacterial opsonophagocytosis, which is known to be required to eliminate encapsulated extracellular pathogens, such as S. suis [21, 31, 32]. In contrast, IgG1 (called "type 2 IgG subclass") elicited during IL-4-dominant Th2 immune responses, usually has a less protective potential [33]. In pigs, the functionality of the different IgG subclasses has not been well characterized, in part due to the lack of appropriate reagents to differentiate the complexity of swine Ig allelic variants [34, 35]. Nevertheless, based on available reagents, swine IgG2 has been suggested to correlate with better protection against S. suis infection [31]; yet contradictory results do exist on the swine IgG1 vs. IgG2 specific contribution to protection [26].

Despite the induction of humoral immunity in vaccinated piglets, bacterin formulations with Emulsigen ${ }^{\circledR}$-D $(\mathrm{O} / \mathrm{W})$ and Quil- $^{\circledR}$ (saponin) failed to provide clinical protection against an S. suis serotype 2 experimental challenge and a biased IgG1 antibody response was observed. Emulsigen ${ }^{\circledR}$ and Quil- $\mathrm{A}^{\circledR}$ adjuvants have shown strong induction of humoral immunity and protection in vaccines against other major livestock pathogens [19]. A previous study demonstrated that an S. suis serotype 2 bacterin adjuvanted with Emulsigen ${ }^{\circledR}$ induces protective immunity against homologous challenge. The protective effect correlated with the presence of opsonizing antibody titers against the serotype 2 strain, and a mixed IgG1/IgG2 antibody response against the muramidasereleased protein (used as ELISA antigen) [36]. On the other hand, an experimental sub-unit vaccine using surface antigen one (Sao) as antigen and Emulsigen ${ }^{\circledR}$-Plus as adjuvant induced an IgG1-dominated humoral response 
and did not reflect in the protection of pigs against $S$. suis serotype 2 . The same antigen with another adjuvant (Quil-A ${ }^{\circledR}$ ) was protective [31, 33]. Finally, a S. suis serotype 9 bacterin adjuvanted with Emulsigen ${ }^{\circledR}$ elicited a limited humoral antibody response and did not show an association with clinical protection [37]. Studies on Quil$\mathrm{A}^{\circledR}$ formulated $S$. suis vaccines in swine are scarce and also revealed contradictory results [21]. For instance, as mentioned above, the Sao sub-unit vaccine formulated with Quil- $\mathrm{A}^{\circledR}$ triggered a strong IgG2 biased, opsonizing antibody response in pigs which conferred efficient protection against challenge infection with $S$. suis serotype 2 [31]. A saponin-adjuvanted bacterin delayed the appearance of the clinical signs and decreased their severity after $S$. suis challenge, although it did not have a significant effect on pig mortality [15]. It should be noted, however, that it is difficult to compare the obtained results on the immunological response amongst these studies. Several factors might influence the outcome of the study for a given vaccine formulation, including the source of the adjuvant and their formulation variations, the coating antigen used for the ELISA test and/or the ELISA procedure used to calculate antibody titers. Another option that could be further explored is the combination of Emusligen ${ }^{\circledR}$-D with aluminum hydroxide or Quil- $\mathrm{A}^{\circledR}$. The combination of these adjuvants could potentially increase immune response as reported in previous vaccination studies against foot-and-mouth disease in pigs [38]. The obstacle to creating a vaccine with a combination of adjuvants against diseases in swine is mainly economic; the cost-benefit of such a combination should be evaluated.

Montanide $^{\mathrm{TM}}$ adjuvants are commercial $\mathrm{W} / \mathrm{O}$ or $\mathrm{W} / \mathrm{O} / \mathrm{W}$ emulsions used to formulate animal vaccines against different livestock diseases [39, 40]. In cattle, inactivated vaccines against foot-and-mouth disease formulated with Montanide $^{\mathrm{TM}}$ ISA $61 \mathrm{VG}$, Montanide ${ }^{\mathrm{TM}}$ ISA 201 VG, or Montanide 206 ISA VG, all induced a longlived immunity; however, vaccines formulated with Montanide $^{\mathrm{TM}}$ ISA $201 \mathrm{VG}$ showed a more rapid onset of the immune response and the highest level of cellular immunity and a mixed IgG1/IgG2 immune response [39-41]. In our work, S. suis vaccines formulated with one of these three Montanide ${ }^{\mathrm{TM}}$ adjuvants also induced a mixed IgG1/ IgG2 immune response. Bacterin vaccines formulated with Montanide ${ }^{\mathrm{TM}}$ ISA 201 VG or Montanide ${ }^{\mathrm{TM}}$ ISA 206 VG showed similar results characterized by partial, albeit not significant, clinical protection compared to the corresponding placebos. These results could be expected since both adjuvants are $\mathrm{W} / \mathrm{O} / \mathrm{W}$ emulsions and thus have a similar mechanism of immune stimulation. On the other hand, vaccine formulation with Montanide ${ }^{\mathrm{TM}}$ ISA $61 \mathrm{VG}$ showed maximal protection and significant reduction of clinical signs against a homologous $S$. suis challenge and high antibody levels. Our results corroborate a recent study, where inactivated Listeria monocytogenes emulsified with Montanide ${ }^{\mathrm{TM}}$ ISA 61 VG showed increased induction of antibody titers, higher IgG2a/IgG1 ratios, and $100 \%$ protection against challenge in a murine model [42]. Studies on the effect of Montanide ${ }^{\mathrm{TM}}$ adjuvants on the efficacy of S. suis vaccines are scarce. A comparative study reported that a Montanide ${ }^{\mathrm{TM}}$ ISA 50 (W/O) adjuvanted $S$. suis bacterin appears to be more efficacious than a Montanide ISA $25(\mathrm{O} / \mathrm{W})$ formulation in delaying the onset of mortality, and decreasing clinical signs and lesions associated with $S$. suis serotype 2 challenge infection [15].

Another interesting finding of our study is that neither of the tested bacterin vaccine formulations induced an increase of antibodies against S. suis CPS. S. suis CPS is regarded as an important virulence factor that facilitates survival of the bacteria during infection, and thus an important target of protective antibodies [17, 20]. Similarly, an S. suis serotype 2 bacterin adjuvanted with Stimune ${ }^{\circledR}$ failed to induce anti-CPS antibodies [17]; confirming the poor immunogenicity of the CPS, event when associated with the bacterial surface [43-45]. Indeed, the ability of $S$. suis bacterins to induce this type of antibody is controversial [13, 21,36, 46]. Therefore, the observed clinical protection after piglet vaccination with the bacterin formulated with Montanide ${ }^{\text {TM }}$ ISA 61 VG could not be correlated to the presence of anti-CPS antibodies. In this case, protective antibodies are probably directed against surface-exposed bacterial proteins [21].

Taken together the results from our study indicate that the type of adjuvant formulation has paramount importance on the efficacy and protection of bacterinbased vaccines against $S$. suis serotype 2 . The bacterin vaccine formulated with Montanide ${ }^{\mathrm{TM}}$ ISA 61 VG was the only formulation able to provide clear significant protection against homologous challenge and reduced morbidity. It must be noted that the IP challenge dose and route used in this model are extremely high and aggressive. The goal of this challenge model was to represent the exacerbated systemic infection, thus the level of protection provided by the vaccine formulated with Montanide $^{\mathrm{TM}}$ ISA $61 \mathrm{VG}$ in this experimental challenge would certainly be adequate during natural infection in the field. It should be noted that almost all piglets are early colonized by $S$. suis and it is not known how this early colonization may affect the response against a vaccine. Therefore, more studies confirming the data obtained in the current study are necessary.

\section{Abbreviations}

CPS: capsular polysaccharide; CNS: central nervous system; id: identification; IM: intramuscularly; IP: intraperitoneal; O/W: oil-in-water; PBS: 
phosphate-buffered saline; PBS-T: PBS-tween; RT: room temperature; Sao: surface antigen one; THB: Todd-Hewitt broth; TMB: tetramethylbenzidine; W/O: water-in-oil; W/O/W: water-in-oil-in-water.

\section{Supplementary Information}

The online version contains supplementary material available at https://doi. org/10.1186/s13567-021-01004-x.

\section{Additional file 1. Experimental design of the study. Experimental} design of the study for evaluation of immunogenicity and protection of bacterin vaccines formulated with different adjuvants. The experimental design was consistent for all tested vaccine formulations. IP; intraperitoneal injection

Additional file 2. Typical clinical signs of S. suis disease observed in piglets. Typical clinical signs of S. suis disease observed in piglets from the placebo Montanide ${ }^{\mathrm{TM}}$ ISA 61 VG control group. The intraperitoneal challenge model used in this experimental study was able to reproduce typical S. suis clinical signs of meningitis (head inclination and incoordination) (A); lameness, swollen joints (black arrow), and polyarthritis (B); and characteristic lesions of fibrinopurulent exudate in swollen joints observed during necropsy (black arrow) (C). S. suis serotype 2 was isolated from the joint cavities, meninges, liver and spleen of diseased animals. Pigs having a clinical score $=3$ were humanely euthanized

\section{Acknowledgements}

We thank Guy Beauchamp (Biostatistics Office, Faculty of Veterinary Medicine, University of Montreal) for his support with statistical analysis.

\section{Authors' contributions}

MO, LC, DD, MG, and MS were involved in study conduct and study interpretation; $M O, M G$, and $M S$ were involved in study design; $M O, M G$, and $M S$ were involved in writing, reviewing, and editing; DD was involved in study statistical analyses and graphs' conception. MS and MG obtained the funding for the experimental work. All authors read and approved the final manuscript.

\section{Funding}

This work was mainly supported by The Ontario Pork Producers (no. OP 19-006 to M.S. and M.G.) and the Programme Innov'Action agroalimentaire of the Ministère de l'Agriculture, des Pêcheries et de l'Alimentation (MAPAQ) grant (no. IA1 19059 to M.G. and M.S.). Partial support was provided by Les Éleveurs de porcs du Québec (no. RQ000674 to M.S.) and the Natural Sciences and Engineering Research Council of Canada (NSERC) through grants to M.S. and M.G. (nos. 342150 and 04435, respectively). Scholarships were also provided to L.C. by the Swine and Poultry Infectious Diseases Research Centre supported by the Fonds de recherche du Québec - Nature et technologies (FRQNT, grant no. RS-170946). L.C. is also the recipient of a Zoetis graduate student scholarship. D.D. is a recipient of a FRQNT fellowship. M.S. is a holder of a Canada Research Chair - Tier 1.

\section{Availability of data and materials}

The materials and data not presented in this manuscript are available from the corresponding author upon request.

\section{Declarations}

\section{Ethics approval and consent to participate}

All experiments involving animals were conducted in accordance with the guidelines and policies of the Canadian Council on Animal Care and the principles set forth in the Guide for the Care and the Use of Laboratory Animals by the Animal Welfare Committee of the University of Montreal, which approved the protocols and procedures used herein (Permit Number RECH-2014). A total of 120 pigs were used in this study.

\section{Competing interests}

The authors declare that they have no competing interests.
Received: 12 September 2021 Accepted: 1 October 2021

Published online: 19 October 2021

\section{References}

1. Okura M, Osaki M, Nomoto R, Arai S, Osawa R, Sekizaki T, Takamatsu D (2016) Current taxonomical situation of Streptococcus suis. Pathogens 5:45

2. Gottschalk M, Segura M (2019) Streptococcocis. In: Zimmerman JJ, Karriker LA, Ramirez A, Schwartz KJ, Stevenson GW, Zhang J (eds) Diseases of Swine. Wiley-Blackwell, Hoboken, NJ, USA, pp 934-950

3. Baele M, Chiers K, Devriese LA, Smith HE, Wisselink HJ, Vaneechoutte M, Haesebrouck F (2001) The gram-positive tonsillar and nasal flora of piglets before and after weaning. J Appl Microbiol 91:997-1003

4. O'Sullivan T, Friendship R, Blackwell T, Pearl D, McEwen B, Carman S, Slavic D, Dewey C (2011) Microbiological identification and analysis of swine tonsils collected from carcasses at slaughter. Can J Vet Res 75:106-111

5. Goyette-Desjardins G, Auger JP, Xu J, Segura M, Gottschalk M (2014) Streptococcus suis, an important pig pathogen and emerging zoonotic agent-an update on the worldwide distribution based on serotyping and sequence typing. Emerg Microbes Infect 3:e45

6. Estrada AA, Gottschalk M, Rossow S, Rendahl A, Gebhart C, Marthaler DG (2019) Serotype and genotype (Multilocus Sequence Type) of Streptococcus suis isolates from the United States serve as predictors of pathotype. J Clin Microbiol 57:e00377-e419

7. Gottschalk M, Xu J, Calzas C, Segura M (2010) Streptococcus suis: a new emerging or an old neglected zoonotic pathogen? Future Microbiol 5:371-391

8. Wertheim HF, Nghia HD, Taylor W, Schultsz C (2009) Streptococcus suis: an emerging human pathogen. Clin Infect Dis 48:617-625

9. Seitz M, Valentin-Weigand P, Willenborg J (2016) Use of antibiotics and antimicrobial resistance in veterinary medicine as exemplified by the swine pathogen Streptococcus suis. Curr Top Microbiol Immunol 398:103-121

10. Obradovic MR, Segura M, Segales J, Gottschalk M (2021) Review of the speculative role of co-infections in Streptococcus suis-associated diseases in pigs. Vet Res 52:49

11. Rieckmann K, Pendzialek SM, Vahlenkamp T, Baums CG (2020) A critical review speculating on the protective efficacies of autogenous Streptococcus suis bacterins as used in Europe. Porcine Health Manag 6:12

12. Hoelzer K, Bielke L, Blake DP, Cox E, Cutting SM, Devriendt B, ErlacherVindel E, Goossens E, Karaca K, Lemiere S, Metzner M, Raicek M, Collell Surinach M, Wong NM, Gay C, Van Immerseel F (2018) Vaccines as alternatives to antibiotics for food producing animals. Part 2: new approaches and potential solutions. Vet Res 49:70

13. Corsaut L, Misener M, Canning P, Beauchamp G, Gottschalk M, Segura M (2020) Field study on the immunological response and protective effect of a licensed autogenous vaccine to control Streptococcus suis infections in post-weaned piglets. Vaccines 8:384

14. Wisselink HJ, Vecht U, Stockhofe-Zurwieden N, Smith HE (2001) Protection of pigs against challenge with virulent Streptococcus suis serotype 2 strains by a muramidase-released protein and extracellular factor vaccine. Vet Rec 148:473-477

15. Pallares FJ, Schmitt CS, Roth JA, Evans RB, Kinyon JM, Halbur PG (2004) Evaluation of a ceftiofur-washed whole cell Streptococcus suis bacterin in pigs. Can J Vet Res 68:236-240

16. Auger JP, Fittipaldi N, Benoit-Biancamano MO, Segura M, Gottschalk M (2016) Virulence studies of different sequence types and geographical origins of Streptococcus suis serotype 2 in a mouse model of infection. Pathogens 5:48

17. Goyette-Desjardins G, Calzas C, Shiao TC, Neubauer A, Kempker J, Roy R, Gottschalk M, Segura M (2016) Protection against Streptococcus suis serotype 2 infection using a capsular polysaccharide glycoconjugate vaccine. Infect Immun 84:2059-2075

18. Van Calsteren MR, Goyette-Desjardins G, Gagnon F, Okura M, Takamatsu D, Roy R, Gottschalk M, Segura M (2016) Explaining the serological characteristics of Streptococcus suis serotypes 1 and 1/2 from their capsular polysaccharide structure and biosynthesis. J Biol Chem 291:8387-8398

19. Charerntantanakul W (2020) Adjuvants for swine vaccines: mechanisms of actions and adjuvant effects. Vaccine 38:6659-6681 
20. Segura M, Fittipaldi N, Calzas C, Gottschalk M (2017) Critical Streptococcus suis virulence factors: are they all really critical? Trends Microbiol 25:585-599

21. Segura M (2015) Streptococcus suis vaccines: candidate antigens and progress. Expert Rev Vaccines 14:1587-1608

22. Pomorska-Mol M, Markowska-Daniel I, Rachubik J, Pejsak Z (2011) Effect of maternal antibodies and pig age on the antibody response after vaccination against Glassers disease. Vet Res Commun 35:337-343

23. Lapointe L, D'Allaire S, Lebrun A, Lacouture S, Gottschalk M (2002) Antibody response to an autogenous vaccine and serologic profile for Streptococcus suis capsular type 1/2. Can J Vet Res 66:8-14

24. Arndt ER, Farzan A, Slavic D, Maclnnes Jl, Friendship RM (2018) An epidemiological study of Streptococcus suis serotypes of pigs in Ontario determined by a multiplex polymerase chain reaction. Can Vet J 59:997-1000

25. Corsaut L, Martelet L, Goyette-Desjardins G, Beauchamp G, Denicourt M Gottschalk M, Segura M (2021) Immunogenicity study of a Streptococcus suis autogenous vaccine in preparturient sows and evaluation of passive maternal immunity in piglets. BMC Vet Res 17:72

26. Baums CG, Bruggemann C, Kock C, Beineke A, Waldmann KH, ValentinWeigand P (2010) Immunogenicity of an autogenous Streptococcus suis bacterin in preparturient sows and their piglets in relation to protection after weaning. Clin Vaccine Immunol 17:1589-1597

27. Martinez-Miro S, Tecles F, Ramon M, Escribano D, Hernandez F, Madrid J, Orengo J, Martinez-Subiela S, Manteca X, Ceron JJ (2016) Causes, consequences and biomarkers of stress in swine: an update. BMC Vet Res 12:171

28. Torremorell M, Pijoan C, Trigo E (1997) Vaccination against Streptococcus suis: Effect on nursery mortality. Swine Health Prod 5:139-143

29. Shardlow E, Mold M, Exley C (2018) Unraveling the enigma: elucidating the relationship between the physicochemical properties of aluminiumbased adjuvants and their immunological mechanisms of action. Allergy Asthma Clin Immunol 14:80

30. HogenEsch H, O'Hagan DT, Fox CB (2018) Optimizing the utilization of aluminum adjuvants in vaccines: you might just get what you want. NP. Vaccines 3:51

31. LiY, Gottschalk M, Esgleas M, Lacouture S, Dubreuil JD, Willson P, Harel J (2007) Immunization with recombinant Sao protein confers protection against Streptococcus suis infection. Clin Vaccine Immunol 14:937-943

32. Kock C, Beineke A, Seitz M, Ganter M, Waldmann KH, Valentin-Weigand P, Baums CG (2009) Intranasal immunization with a live Streptococcus suis isogenic ofs mutant elicited suilysin-neutralization titers but failed to induce opsonizing antibodies and protection. Vet Immunol Immunopathol 132:135-145

33. Li Y, Martinez G, Gottschalk M, Lacouture S, Willson P, Dubreuil JD, Jacques M, Harel J (2006) Identification of a surface protein of Streptococcus suis and evaluation of its immunogenic and protective capacity in pigs. Infect Immun 74:305-312

34. Kloep A, Wertz N, Mendicino M, Ramsoondar J, Butler JE (2012) Linkage haplotype for allotypic variants of porcine IgA and lgG subclass genes. Immunogenetics 64:469-473
35. Butler JE, Wertz N, Deschacht N, Kacskovics I (2009) Porcine IgG: structure, genetics, and evolution. Immunogenetics 61:209-230

36. Baums CG, Kock C, Beineke A, Bennecke K, Goethe R, Schroder C, Waldmann KH, Valentin-Weigand P (2009) Streptococcus suis bacterin and subunit vaccine immunogenicities and protective efficacies against serotypes 2 and 9. Clin Vaccine Immunol 16:200-208

37. Buttner $\mathrm{N}$, Beineke $\mathrm{A}$, de Buhr $\mathrm{N}$, Lilienthal S, Merkel J, Waldmann $\mathrm{KH}$, Valentin-Weigand P, Baums CG (2012) Streptococcus suis serotype 9 bacterin immunogenicity and protective efficacy. Vet Immunol Immunopathol 146:191-200

38. Park ME, Lee SY, Kim RH, Ko MK, Lee KN, Kim SM, Kim BK, Lee JS, Kim B, Park JH (2014) Enhanced immune responses of foot-and-mouth disease vaccine using new oil/gel adjuvant mixtures in pigs and goats. Vaccine 32:5221-5227

39. Dar P, Kalaivanan R, Sied N, Mamo B, Kishore S, Suryanarayana VV, Kondabattula G (2013) Montanide ISA 201 adjuvanted FMD vaccine induces improved immune responses and protection in cattle. Vaccine 31:3327-3332

40. Khorasani A, Madadgar O, Soleimanjahi H, Keyvanfar H, Mahravani H (2016) Evaluation of the efficacy of a new oil-based adjuvant ISA 61 VG FMD vaccine as a potential vaccine for cattle. Iran J Vet Res 17:8-12

41. Ibrahim Eel S, Gamal WM, Hassan Al, Mahdy Sel D, Hegazy AZ, Abdel-Atty MM (2015) Comparative study on the immunopotentiator effect of ISA 201, ISA 61, ISA 50, ISA 206 used in trivalent foot and mouth disease vaccine. Vet World 8:1189-1198

42. Zhu T, Meng F, Yao H, Wang Y, Jiao X, Yin Y (2020) ISA 61 VG adjuvant enhances protective immune response of Listeria monocytogenes inactivated vaccine. Sheng Wu Gong Cheng Xue Bao 36:1378-1385 (in Chinese)

43. Goyette-Desjardins G, Auger JP, Dolbec D, Vinogradov E, Okura M, Takamatsu D, Van Calsteren MR, Gottschalk M, Segura M (2020) Comparative study of immunogenic properties of purified capsular polysaccharides from Streptococcus suis serotypes 3, 7, 8, and 9: the serotype 3 polysaccharide induces an opsonizing IgG response. Infect Immun 88:e00377

44. Calzas C, Lemire P, Auray G, Gerdts V, Gottschalk M, Segura M (2015) Antibody response specific to the capsular polysaccharide is impaired in Streptococcus suis serotype 2-infected animals. Infect Immun 83:441-453

45. Calzas C, Taillardet M, Fourati IS, Roy D, Gottschalk M, Soudeyns H, Defrance T, Segura M (2017) Evaluation of the immunomodulatory properties of Streptococcus suis and Group B Streptococcus capsular polysaccharides on the humoral response. Pathogens 6:16

46. Wisselink HJ, Stockhofe-Zurwieden N, Hilgers LA, Smith HE (2002) Assessment of protective efficacy of live and killed vaccines based on a non-encapsulated mutant of Streptococcus suis serotype 2. Vet Microbiol 84:155-168

\section{Publisher's Note}

Springer Nature remains neutral with regard to jurisdictional claims in published maps and institutional affiliations.

\footnotetext{
Ready to submit your research? Choose BMC and benefit from:

- fast, convenient online submission

- thorough peer review by experienced researchers in your field

- rapid publication on acceptance

- support for research data, including large and complex data types

- gold Open Access which fosters wider collaboration and increased citations

- maximum visibility for your research: over $100 \mathrm{M}$ website views per year
}

At BMC, research is always in progress.

Learn more biomedcentral.com/submissions 